\title{
MOLECULAR VOLUMES AND EXPANSIVITIES OF LIQUID NORMAL HYDROGEN AND PARAHYDROGEN
}

\author{
By Russell B. Scott and Ferdinand G. Brickwedde
}

\section{ABSTRACT}

The molecular volumes at saturation of liquid normal hydrogen and parahydrogen between $14^{\circ}$ and $20.4^{\circ} \mathrm{K}$ were measured with a fused-quartz dilatometer, the amount of hydrogen being determined from the pressure of the gas in a calibrated flask at a measured temperature. The results are represented by the equations:

$$
\begin{aligned}
& V\left(n-\mathrm{H}_{2}\right) \mathrm{cm}^{3} \mathrm{~mole}^{-1}=24.747-0.08005 T+0.012716 T^{2} \\
& V\left(p-\mathrm{H}_{2}\right) \mathrm{cm}^{3} \mathrm{~mole}^{-1}=24.902-0.0888 T+0.013104 T^{2}
\end{aligned}
$$

At the normal boiling point of $n-\mathrm{H}_{2}\left(20.38^{\circ} \mathrm{K}\right), V\left(n-\mathrm{H}_{2}\right)=28.397 \pm 0.010$ and $\Delta V(p-n)=0.138 \pm 0.010$. The expansivity of $p-\mathrm{H}_{2}$ is only slightly greater than that of $n-\mathrm{H}_{2}$.

The change observed in the molecular volumes of $\mathrm{H}_{2}$ in passing from the state in which the molecules rotate $\left(o-\mathrm{H}_{2}\right)$ to the state in which they do not rotate $\left(p-\mathrm{H}_{2}\right)$ is opposite in direction to the change observed in other substances when passing between these two states of molecular rotation and nonrotation. The changes in "lattice" energies are also of opposite sign. It is shown that the random state of orientation of the axes of $p-\mathrm{H}_{2}$ molecules makes the state of nonrotating $p-\mathrm{H}_{2}$ fundamentally like that of rotation in other substances at high temperatures.

\section{CONTENTS}

I. Introduction

II. Apparatus and method of measurement_ _ _

III. Results . . . .

IV. Theoretical considerations _...

\section{INTRODUCTION}

Some recent investigations of X-ray diffraction, dielectric constants, and specific heats show that the molecules of a number of substances in a condensed phase are oriented. These experiments have shown also that at a certain temperature, characteristic of the material, the oscillatory motion of the molecules about the direction of orientation changes to molecular rotation. This change is accompanied by an increase in molecular volume and in the energy of the condensed phase (hump on the specific-heat curve), the state of molecular rotation having the larger volume and larger energy.

In liquid parahydrogen, $p-\mathrm{H}_{2}$, below $20^{\circ} \mathrm{K}$, there is no molecular rotation since practically all the molecules are in the state whose rotational quantum number, $j$, is 0 , whereas in liquid orthohydrogen, $o-\mathrm{H}_{2}, \quad(j=1)$ there is "free" molecular rotation, which is demonstrated by the fact that the difference in energies of the rotational levels is the same in the liquid and gaseous phases. ${ }^{1}$ The variation with

1 J. C. McLennan and J. H. MeLeod, Roy. Soc. Canada, Trans. 23, section 3, 19-20 (1929). 
temperature of the difference in vapor pressure of these two forms of hydrogen reveals a difference in the "lattice" energies of the condensed state, and one is led to expect a difference in molecular volumes also. The condensed state of $o-\mathrm{H}$ has the lower "lattice" energy although it has the greater total energy, and it has now been found that it has also the smaller molecular volume. Thus it is seen that in the case of liquid hydrogen, the change from the state in which the molecules do not rotate $\left(p-\mathrm{H}_{2}\right)$ to the state in which they do rotate $\left(o-\mathrm{H}_{2}\right)$ is accompanied by a decrease in the molecular volume and "lattice" energy of the condensed state. This is opposite to the direction of the change in the other substances that have been investigated.

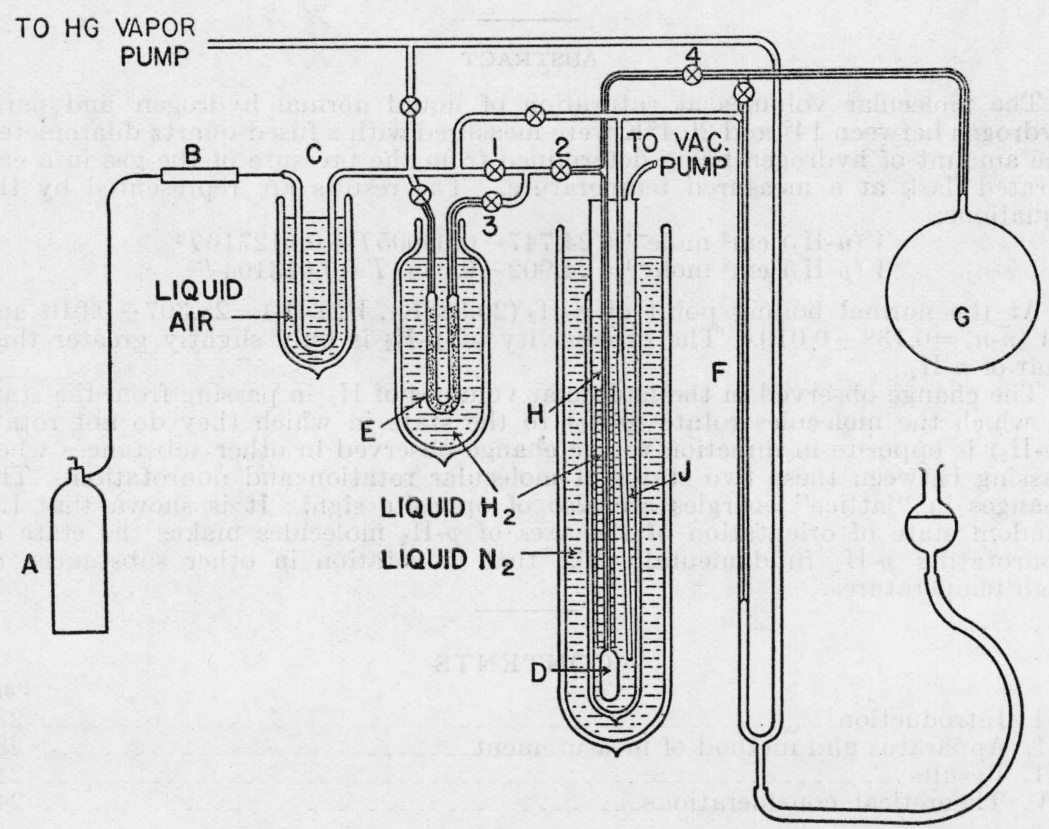

Figure 1.-Diagram of apparatus used to measure the molecular volumes.

$A$, cylinder of hydrogen; $B$, tube containing copper gauze; $C$, U-tube containing cotton; $D$, dilatometer; $E$, catalyst; $F$, Hg manometer; $G, 3$-liter calibrated flask; $H$, fused-quartz capillary; $J$, vapor-pressure tube.

It will be brought out in the discussion that the condensed state of nonrotating $p-\mathrm{H}_{2}$ is fundamentally like that of molecular rotation in the other substances investigated, the state of rotating $o-\mathrm{H}_{2}$ corresponding to the state of molecular orientation in other substances.

The measurements were made on normal hydrogen (75 percent $o-\mathrm{H}_{2}$ ), and $20.4^{\circ} \mathrm{K}$ temperature equilibrium hydrogen $\left(99.8 \text { percent } p-\mathrm{H}_{2}\right)^{2}{ }^{2}$ Careful measurements of the density and expansivity of liquid hydrogen had previously been made by Onnes and Crommelin, ${ }^{3}$ but these measurements were made before the ortho and para forms of $\mathrm{H}_{2}$ had been discovered, whereas it is now known that liquid normal $\mathrm{H}_{2}$ changes at an appreciable rate by conversion of the ortho constituent into $p-\mathrm{H}_{2}$. The molecular volume and expansivity of liquid normal $\mathrm{H}_{2}$ were, therefore, carefully redetermined. The molecular volume and expansivity of liquid $p-\mathrm{H}_{2}$ were measured in the same apparatus.

${ }^{2}$ Harkness and Deming, J. Am. Chem. Soc. 54, 2850 (1932).

3 Onnes and Crommelin, Leiden Comm. 137a (1913). 


\section{APPARATUS AND METHOD OF MEASUREMENT}

The apparatus used is shown diagrammatically in figure 1. Electrolytic hydrogen of high purity, containing less than 0.02 mole percent of air, from cylinder $A$ was passed over copper gauze in tube $B$ at $600^{\circ} \mathrm{C}$ to remove oxygen and insure the normal concentration of the ortho and para varieties. It then passed through a cotton filter in the U-tube $C$, which was surrounded by liquid air, to remove water vapor. When measurements were to be made on normal hydrogen, the hydrogen was then allowed to pass through stopcocks 1 and 2 directly to the calibrated fused-quartz dilatometer $D$, of about $3-\mathrm{cm}^{3}$ capacity, Parahydrogen was obtained by condensing hydrogen in the U-tube $E$ containing zinc chromite, an ortho-para conversion catalyst. ${ }^{5}$ After allowing it to stand in contact with the catalyst at liquid-hydrogen temperatures $1 \frac{1}{2}$ to 4 hours, for complete conversion, the parahydrogen was transferred into the dilatometer by opening stopcocks 3 and 2 and reducing the pressure above the hydrogen bath $H$ by means of a vacuum pump. The molecular volume obtained for parahydrogen was the same whether the hydrogen had been in contact with the catalyst $1 \frac{1}{2}$ or 4 hours, indicating that the conversion to the low-temperature equilibrium concentration was complete.

In order to determine the temperature of the liquid-hydrogen bath surrounding the dilatometer, normal hydrogen was condensed in the tube $J$ and its vapor pressure was read on manometer $F$. An electrical heater at the bottom of the liquid-hydrogen bath caused boiling and promoted uniformity of temperature. ${ }^{6}$ The volume of the condensed hydrogen was determined by reading the position of the liquid meniscus in the tube of the dilatometer by means of a scale fastened to the tube. The flasks surrounding the dilatometer were unsilvered. Reference marks on the fused-quartz dilatometer tube provided a means of determining the length of the scale at liquidhydrogen temperature. The volume of the liquid was measured at several temperatures, obtained by adjusting the pressure over the liquid-hydrogen bath.

The amount of hydrogen used was determined from measurements of the pressure and temperature of the gas in a flask of known volume. After the measurements of the volume of the liquid in the dilatometer were completed stopcock 4 was opened and the hydrogen allowed to evaporate into flask $G$. The tube $J$ and manometer $F$ were evacuated and the whole apparatus allowed to warm up to room temperature overnight. The next day the pressure of the hydrogen in flask $G$ was measured with the manometer $F$. The flask was surrounded by a stirred, insulated water bath at approximately room temperature. A careful determination of the volume of the flask and connecting tubes was made after all other measurements were completed. The volume outside the water bath was only about $18 \mathrm{~cm}^{3}$, the volume of the flask $G$ being $3,264 \mathrm{~cm}^{3}$. The volume of the hydrogen at $0^{\circ} \mathrm{C}$ and 1 atmosphere was computed from readings of the pressure in the flask $G$

\footnotetext{
4 H. Diamond, Thesis, Princeton University (1935).

$\checkmark$ Brickwedde, Scott, and Taylor, J. Research NBS 15, 463 (1935), RP\&41; J. Chem. Phys. 3, 653 (1y35).

- In order to be certain that the heater did not raise the temperature of the bulb above that of the bath, a number of volume determinations were made with the heater current turned off during the readings. No difference was observed. However, if the heater was not used at all, superheating of the bath caused randorn scattering of the results.
} 
at the temperature of the water bath, using the $P-V-T$ relations for hydrogen given in the International Critical Tables. ${ }^{7}$ A small correction, about $0.2 \mathrm{~cm}^{3}$, was necessary to compensate for the change in volume of the flask with pressure, since the amount of hydrogen used produced a pressure of about $630 \mathrm{~mm}$ of $\mathrm{Hg}$ instead of 1 atmosphere.

The expansion of the fused-quartz dilatometer between $20^{\circ} \mathrm{C}$ and liquid-hydrogen temperature was taken as 0.000165 , which is the mean of some unpublished measurements of this laboratory on three different specimens of fused quartz. A correction had to be made for the hydrogen vapor above the liquid in the capillary tube of the dilatometer. The part of this correction which arises from that section of the tube $(0.75-\mathrm{mm}$ bore) extending from the top of the liquid-hydrogen bath to the part at room temperature was somewhat uncertain since the temperature along the tube was estimated. However, the correction for this intermediate section amounted to only about 0.012 percent of the final result.

The readings on the vapor pressure of normal hydrogen, from which the temperatures were calculated, were corrected for the uncatalyzed ortho to para conversion of liquid hydrogen, in accordance with measurements made previously of the change in the vapor pressure of hydrogen with time. ${ }^{8}$ After the limiting volume of parahydrogen had been determined, a similar correction was made for the change in volume of liquid normal hydrogen with time, which also results from the uncatalyzed ortho to para conversion.

\section{RESULTS}

The molecular volume of the liquid was calculated from the experimentally determined ratios of the volume of the gas to the volume of the liquid, $V_{\text {gas }} / V_{11 \text { q }}$, using $22,428 \mathrm{~cm}^{3}$ mole $\mathrm{e}^{-1}$ as the molecular volume of hydrogen at $0^{\circ} \mathrm{C}$ and 1 normal atmosphere. This value for the molecular volume of hydrogen was computed from the volume of an ideal gas, $22,414 \mathrm{~cm}^{3}$ mole $^{-1} 9$, at the same temperature and pressure and the value ${ }^{10} 0.99939$ for $1+\lambda$, defined by the equation

$$
1+\lambda=\frac{p_{0} V_{0}\left(0^{\circ} \mathrm{C}, 0 \mathrm{~atm}\right)}{p_{1} V_{1}\left(0^{\circ} \mathrm{C}, 1 A_{n}\right)}
$$

Table 1 contains the results of the measurements on normal hydrogen. The temperatures given in column 3 were calculated from the corresponding corrected vapor pressures of normal hydrogen, column 2 , by means of the following vapor-pressure equation, used in previous papers:

$$
\log _{10} P(\mathrm{~mm} \text { of } \mathrm{Hg})=4.6633-\frac{44.7291}{T}+0.02023 T
$$

It was found that the volume-temperature relations of liquid normal hydrogen and liquid parahydrogen at their respective saturation pressures could be represented by a quadratic equation of the form:

$$
V=A+B T+C T^{2}
$$

\footnotetext{
7 3, 4 (1928).

8 Scott, Brickwedde, Urey, and Wahl, J. Chem. Phys. ₹, 458 (1934).

- Birge, Phys. Rev. Supp. 1, no. 1 (1929).

10 International Critical Tables 3, 3 (1928).
} 
TABLE 1.-Molecular volume of liquid normal hydrogen at saturation pressure (experimental data)

\begin{tabular}{|c|c|c|c|c|c|c|}
\hline \multicolumn{2}{|r|}{ Date (1936) } & \multirow{2}{*}{$\begin{array}{r}P\left(n-\mathrm{H}_{2}\right)^{\mathrm{s}} \\
\mathrm{mm} \text { of } \mathrm{Hg}_{749.8}^{\mathrm{H}} \\
65.0\end{array}$} & \multirow{2}{*}{$\begin{array}{l}T \\
{ }^{\circ} \mathrm{K} \\
20.34 \\
14.25\end{array}$} & \multirow{2}{*}{$\begin{array}{r}V_{\text {gas }} / V_{\text {liq }}^{\mathrm{a}} \\
(\text { Observed }) \\
\\
\\
\\
789.87 \\
856.71\end{array}$} & \multirow{2}{*}{$\begin{array}{c}V_{\text {liq }}(\mathrm{obs}) \\
\mathrm{cm}^{3} \mathrm{~mole}^{-1} \\
28.395 \\
26.179\end{array}$} & \multirow{2}{*}{$\begin{array}{c}\Delta V_{\text {liq }} \\
(\mathrm{obs}-\text { cale }) \\
\begin{array}{r}\mathrm{cm}^{3} \mathrm{~mole}^{-1} \\
+0.015 \\
-.009\end{array}\end{array}$} \\
\hline July & 15 & & & & & \\
\hline & $\begin{array}{l}23 \\
23 \\
23 \\
23 \\
23 \\
23\end{array}$ & $\begin{array}{r}754.1 \\
65.4 \\
220.0 \\
335.3 \\
518.8 \\
751.4\end{array}$ & $\begin{array}{l}20.35 \\
14.26 \\
16.81 \\
17.89 \\
19.15 \\
20.34\end{array}$ & $\begin{array}{l}790.10 \\
855.79 \\
830.67 \\
819.04 \\
804.75 \\
790.00\end{array}$ & $\begin{array}{l}28.386 \\
26.207 \\
27.000 \\
27.383 \\
27.870 \\
28.390\end{array}$ & $\begin{array}{l}+.002 \\
+.016 \\
+.005 \\
-.002 \\
-.007 \\
+.010\end{array}$ \\
\hline & $\begin{array}{l}30 \\
30 \\
30 \\
30 \\
30 \\
30 \\
30 \\
30 \\
30\end{array}$ & $\begin{array}{r}752.4 \\
81.7 \\
108.7 \\
201.8 \\
308.9 \\
410.2 \\
571.8 \\
751.7\end{array}$ & $\begin{array}{l}20.35 \\
14.67 \\
15.24 \\
16.60 \\
17.67 \\
18.46 \\
19.45 \\
20.34\end{array}$ & $\begin{array}{l}790.03 \\
852.36 \\
846.72 \\
832.87 \\
821.30 \\
812.79 \\
800.73 \\
790.08\end{array}$ & $\begin{array}{l}28.389 \\
26.313 \\
26.488 \\
26.930 \\
27.308 \\
27.594 \\
28.009 \\
28.387\end{array}$ & $\begin{array}{l}+.005 \\
+.004 \\
+.008 \\
+.008 \\
+.005 \\
+.009 \\
+.009 \\
+.007\end{array}$ \\
\hline August & $\begin{array}{l}7 \\
7 \\
7 \\
7 \\
7 \\
7\end{array}$ & $\begin{array}{r}758.7 \\
79.5 \\
111.2 \\
186.7 \\
290.7 \\
450.6 \\
550.9 \\
756.9\end{array}$ & $\begin{array}{l}20.37 \\
14.62 \\
15.29 \\
16.42 \\
17.51 \\
18.73 \\
19.34 \\
20.37\end{array}$ & $\begin{array}{l}790.20 \\
853.30 \\
846.59 \\
834.94 \\
823.38 \\
809.78 \\
802.64 \\
790.23\end{array}$ & $\begin{array}{l}28.383 \\
26.284 \\
26.492 \\
26.862 \\
27.239 \\
27.696 \\
27.943 \\
28.382\end{array}$ & $\begin{array}{l}-.010 \\
-.011 \\
-.004 \\
+.001 \\
-.005 \\
-.013 \\
-.012 \\
-.010\end{array}$ \\
\hline
\end{tabular}

- Corrected for the uncatalyzed ortho to para conversion of liquid hydrogen.

The values of the constants $A, B$ and $C$ for liquid normal hydrogen, calculated from the data by the method of least squares, were found to be:

$$
\begin{aligned}
& A=24.747 \\
& B=-0.08005 \\
& C=0.012716
\end{aligned}
$$

Column 6 , table 1 , shows the difference between the observed and calculated volumes of liquid normal bydrogen.

Table 2 shows corresponding results on parahydrogen. The values of the constants in eq 2 representing the molecular volume-temperature relation of liquid parahydrogen, also calculated by the method of least squares, are:

$$
\begin{aligned}
& A=24.902 \\
& B=-0.0888 \\
& C=0.013104
\end{aligned}
$$

Table 3 gives the molecular volume and expansivity $1 / V_{20.38}(d V / d T)$ at saturation pressure of normal and parahydrogen, calculated from eq 2. The densities of $n-\mathrm{H}_{2}$ and $p-\mathrm{H}_{2}$ (table 3) were calculated from the molecular volumes and the molecular weight of $\mathrm{H}_{2}$. The molecular weight of hydrogen containing the normal amount $(\mathrm{D} / \mathrm{H}=$ $1 / 6500$ ) of deuterium is $2.0161 \mathrm{~g} .{ }^{11}$ The molecular weight of pure protium hydrogen $\left(\mathrm{H}_{2}^{1}\right)$ is 2.0158 so that the densities of liquid protium hydrogen are 3 parts in 20,000 less than the densities of naturally occurring hydrogen.

11 The atomic weight of naturally occurring hydrogen (1.00805) used in this paper is based on the mass spectrograph results of Aston and Bainbridge, and the latest values of the relative abundances of the isotopes of hydrogen and oxygen. See F. W. Aston, Nature 137, 357 (1936); K. T. Bainbridge and E. B. Jordan, Bul. Amer. Phys. Soc. 11, 18 (1936); Manian, Urey, and Bleakney, J. Am. Chem. Soc. 56, 2601 (1936); N. T. Hall and T. O. Jones, J. Am. Chem. Soc. 56, 1915 (1936). The value used for the abundance of O17:O16= 0.0004:1. 
TABLE 2.-Molecular volume of liquid parahydrogen at saturation pressure (experimental data)

\begin{tabular}{|c|c|c|c|c|c|}
\hline Date (1936) & $P\left(n-\mathrm{H}_{2}\right)^{\mathrm{a}}$ & $T$ & $\begin{array}{c}V_{\mathrm{gas}} / V_{\text {lia }} \\
\text { (observed) }\end{array}$ & $V_{\text {liq }}(\mathrm{obs})$ & $\begin{array}{c}\Delta V_{\text {lia }} \\
\text { (obs-cal.) }\end{array}$ \\
\hline $\begin{array}{r}\text { August } 27 \\
27 \\
27 \\
27 \\
27 \\
27\end{array}$ & $\begin{array}{r}\mathrm{mm} \text { of } \mathrm{Hg} \\
68.5 \\
117.9 \\
221.8 \\
374.0 \\
633.7 \\
754.2\end{array}$ & $\begin{array}{l}{ }^{\circ} \mathrm{K} \\
14.35 \\
15.41 \\
16.83 \\
18.19 \\
19.78 \\
20.36\end{array}$ & $\begin{array}{l}851.82 \\
841.62 \\
826.97 \\
811.86 \\
793.44 \\
786.16\end{array}$ & $\begin{array}{r}\mathrm{cm}^{3} \text { mole-1 } \\
26.330 \\
26.649 \\
27.121 \\
27.625 \\
28.267 \\
28.529\end{array}$ & \begin{aligned} & $\mathrm{cm}^{3}$ mole-1 \\
&+0.004 \\
&+.004 \\
&+.002 \\
&+.002 \\
& \hdashline .005 \\
&+.003\end{aligned} \\
\hline $\begin{array}{l}28 \\
28 \\
28 \\
28\end{array}$ & $\begin{array}{l}140.5 \\
314.7 \\
567.8 \\
748.3\end{array}$ & $\begin{array}{l}15.78 \\
17.72 \\
19.43 \\
20.33\end{array}$ & $\begin{array}{l}838.33 \\
811.08 \\
797.56 \\
786.57\end{array}$ & $\begin{array}{l}26.753 \\
27.449 \\
28.121 \\
28.514\end{array}$ & $\begin{array}{l}-.009 \\
+.006 \\
-.003 \\
-.003\end{array}$ \\
\hline
\end{tabular}

a Corrected for the uncatalyzed ortho to para conversion of liquid hydrogen.

TABLE 3.-Molecular volumes, coefficients of expansion, and densities of liquid normal and parahydrogen at saturation pressure

\begin{tabular}{|c|c|c|c|c|c|c|c|c|}
\hline \multirow[b]{2}{*}{$T$} & \multicolumn{3}{|c|}{ Normal hydrogen } & \multicolumn{3}{|c|}{ Parahydrogen } & \multicolumn{2}{|c|}{ Difference (para-normal) } \\
\hline & $V$ & $\frac{1}{V_{20.38^{\circ} \mathrm{K}}} \frac{d V}{d T}$ & $\rho$ & $V$ & $\frac{1}{V_{20.38}{ }^{\circ} \mathrm{K}} \frac{d V}{d T}$ & $\rho$ & $\Delta V$ & $\Delta \frac{1}{V_{20.38^{\circ} \mathrm{K}}} \frac{d V}{d T}$ \\
\hline $\begin{array}{c}{ }^{\circ} \mathrm{K} \\
20.38 \\
20.00 \\
19.00 \\
18.00\end{array}$ & $\begin{array}{r}\mathrm{cm}^{3} \mathrm{~mole}^{-1} \\
28.397 \\
28.232 \\
27.816 \\
27.426\end{array}$ & $\begin{array}{c}{ }^{\circ} \mathrm{K}^{-1} \\
0.01543 \\
.01509 \\
.01420 \\
.01330\end{array}$ & $\begin{array}{c}\mathrm{g} \mathrm{cm-3}^{-3} \\
0.07099 \\
.07141 \\
.07248 \\
.07351\end{array}$ & $\begin{array}{r}\mathrm{cm}^{3} \mathrm{~mole}^{-1} \\
28.535 \\
28.368 \\
27.945 \\
27.549\end{array}$ & $\begin{array}{c}{ }^{\circ} \mathrm{K}^{-1} \\
0.01561 \\
.01526 \\
.01434 \\
.01342\end{array}$ & $\begin{array}{c}\mathrm{g} \mathrm{cm-3} \\
0.07065 \\
.07107 \\
.07214 \\
.07318\end{array}$ & $\begin{array}{r}\mathrm{cm}^{3} \text { mole-1 } \\
0.138 \\
.136 \\
.129 \\
.123\end{array}$ & $\begin{array}{r}{ }^{\circ} \mathrm{K}-1 \\
0.00018 \\
.00017 \\
.00014 \\
.00012\end{array}$ \\
\hline $\begin{array}{l}17.00 \\
16.00 \\
15.00 \\
14.00\end{array}$ & $\begin{array}{l}27.061 \\
26.721 \\
26.407 \\
26.119\end{array}$ & $\begin{array}{l}.01241 \\
.01151 \\
.01062 \\
.00972\end{array}$ & $\begin{array}{l}.07450 \\
.07545 \\
.07634 \\
.07719\end{array}$ & $\begin{array}{l}27.179 \\
26.836 \\
26.518 \\
26.227\end{array}$ & $\begin{array}{l}.01250 \\
.01158 \\
.01066 \\
.00975\end{array}$ & $\begin{array}{l}.07417 \\
.07512 \\
.07602 \\
.07687\end{array}$ & $\begin{array}{l}.118 \\
.115 \\
.112 \\
.108\end{array}$ & $\begin{array}{l}.00009 \\
.00007 \\
.00004 \\
.00003\end{array}$ \\
\hline
\end{tabular}

Column 8 shows the difference in molecular volumes of para and normal hydrogen. It is seen that at the normal boiling point of normal hydrogen the molecular volume of parahydrogen is about $0.138 \mathrm{~cm}^{3} \mathrm{~mole}^{-1}$, or 0.49 percent greater than that of normal hydrogen. The values given in column 9 are the differences in expansivities of para and normal hydrogen. The error in these differences in expansivities may be large since their values represent a small difference of two derivatives. They are to be regarded only as indicating the direction and order of magnitude of this difference. The difference in density of normal and parahydrogen is almost constant (column 4column 7). At $20.38^{\circ} \mathrm{K}$ this difference is $0.00034 \mathrm{~g} \mathrm{~cm}^{-3}$ and at $14.00^{\circ} \mathrm{K}$ it is $0.00032 \mathrm{~g} \mathrm{~cm}^{-3}$. The change $0.00002 \mathrm{~g} \mathrm{~cm}^{-3}$ is of the order of magnitude of the probable error of the results.

In estimating the probable error of the results, the deviations of the observed volumes from eq 2 were taken as a measure of that part of the probable error due to accidental errors of observation. This was estimated at \pm 0.02 percent, somewhat less than the mean deviation of the observations. In addition, systematic errors of measurement were considered. The sources of these systematic errors and their probable magnitudes follow.

1. An error in the determination of the volume of that part of the apparatus in which the amounts of gas were measured: 0.01 percent.

2. An error in the determination of the amount of vapor above the liquid in the dilatometer: 0.01 percent. 
3. An error in the correction of the liquid volume and vapor pressure of normal hydrogen for the uncatalyzed ortho to para conversion: 0.01 percent.

4. An error in the determination of the volume of the dilatometer: 0.005 percent.

5. An error caused by a nitrogen impurity in the hydrogen used: 0.0008 percent.

Considering all of the accidental and systematic errors, the probable error of the results is found to be about \pm 0.03 percent. The molecular volumes of liquid normal and parahydrogen at the normal boiling point of normal hydrogen $\left(20.38^{\circ} \mathrm{K}\right.$, according to eq 1$)$ may then be given as:

$$
\begin{aligned}
& V\left(n-\mathrm{H}_{2}\right)=28.397 \pm 0.010 \mathrm{~cm}^{3} \mathrm{~mole}^{-1} . \\
& V\left(p-\mathrm{H}_{2}\right)=28.535 \pm 0.010 \mathrm{~cm}^{3} \mathrm{~mole}^{-1} .
\end{aligned}
$$

The difference between the molecular volumes of para and normal hydrogen, while it is not affected by systematic errors of measurement, includes the accidental errors of two different sets of observations, hence the probable error in the difference is also about $\pm 0.010 \mathrm{~cm}^{3}$ $\mathrm{mole}^{-1}$. Accordingly, the difference in the molecular volumes of $p-\mathrm{H}_{2}$ and $n-\mathrm{H}_{2}$ at the normal boiling point of normal hydrogen is given as

$$
\Delta V\left(p-\mathrm{H}_{2}\right)-n-\mathrm{H}_{2}=0.138 \pm 0.010 \mathrm{~cm}^{3} \mathrm{~mole}^{-1} .
$$

In table 4 the results of our measurements of the molecular volume of liquid normal hydrogen are compared with values calculated from the density of liquid hydrogen as reported by other investigators. Dewar's ${ }^{12}$ value is much the highest. He measured the volume of gaseous hydrogen in a bell-jar gas holder. It is possible that errors in the measurement of volume and temperature of the gas resulted in his high value.

Onnes and Crommelin ${ }^{13}$ made careful measurements, and the difference between their value and that reported in this paper is too great to be accounted for by ordinary errors of observation. The existence of ortho and para varieties of hydrogen was not known at that time and it is probable that their sample of hydrogen contained an excess of parahydrogen. Evidence to this effect is the fact that their value lies between the values reported here for normal and para hydrogen and is somewhat closer to that for normal hydrogen. Although the method of preparation of their hydrogen is not described in the paper ${ }^{14}$ on the density, an earlier communication ${ }^{15}$ describes a method of preparation of pure hydrogen by means of two distillations of liquid hydrogen, the hydrogen thus obtained to be used "for the replenishment of thermometers and piezometers." This method would result in a high concentration of parahydrogen, both because of the ortho to para conversion with time and the fractional separation upon distillation. The measurements of Onnes and Crommelin were made over a range of temperatures, making it possible to calculate coefficients of expansion from their data. At the normal boiling point of normal hydrogen the coefficient of expansion determined from their data is $0.0157\left({ }^{\circ} \mathrm{C}\right)^{-1}$ as compared with our value of $0.0154\left({ }^{\circ} \mathrm{C}\right)^{-1}$.

12 Dewar. Proc. Roy. Soc. [A] 73, 251 (1904)

13 Onnes and Crommelin, Leiden Comm. 137a (1937).

14 See footnote 13 .

is Onnes, Leiden Comm. 94e, p. 59 (1905). 
Augustin ${ }^{16}$ gives the density of liquid hydrogen boiling at a pressure of $745.5 \mathrm{~mm}$ of $\mathrm{Hg}$ as $0.07105 \mathrm{~g} \mathrm{~cm}^{-3}$. Allowing for expansion, this becomes $0.07097 \mathrm{~g} \mathrm{~cm}^{-3}$ at the normal boiling point of normal hydrogen. Augustin's value agrees very well with ours, but this agreement is probably fortuitous since his individual determinations, four in number, range as much as $0.00013 \mathrm{~g} \mathrm{~cm}^{-3}$ above and below the mean value reported.

TABLE 4.-Comparison of results of different observers at the normal boiling point of normal hydrogen

\begin{tabular}{|c|c|c|c|c|}
\hline Observer & Date & Method used & $\begin{array}{l}\text { Density of } \\
\text { liquid } \\
n-\mathrm{H}_{2}\end{array}$ & $\begin{array}{c}\text { Molecular } \\
\text { volume of } \\
\text { liquid } \\
n-\mathrm{H}_{2}\end{array}$ \\
\hline Dewar...... & 1904 & Comparison of volumes of liquid and gas...... & $\begin{array}{l}\mathrm{g} \mathrm{cm}^{-3} \\
0.07002\end{array}$ & $\begin{array}{r}\mathrm{cm}^{3} \mathrm{~mole}^{-1} \\
28.79\end{array}$ \\
\hline Onnes and Crommelin... & 1913 & ..... do & .07086 & 28.45 \\
\hline Augustin & 1914 & Weighing a sinker in liquid hydrogen....... & .07097 & 28.41 \\
\hline Scott and Brickwedde.... & 1937 & Comparison of volumes of liquid and gas...... & .07099 & 28.397 \\
\hline
\end{tabular}

\section{THEORE'TICAL CONSIDERATIONS}

As was pointed out in section I, the sign of the difference in the lattice energies and molecular volumes of the rotating and nonrotating varieties of $\mathrm{H}_{2}$ in a condensed phase is opposite to the sign of the change observed in other substances when passing through the transition from the state of molecular orientation to the state of molecular rotation. The Heisenberg Uncertainty Principle, when applied to the problem of a nonrotating molecule oscillating about a direction of molecular orientation $(\Delta \theta \cdot \Delta[I \hat{\theta}] \sim h)$, shows that for large amplitudes of oscillation, up to $90^{\circ}$, the zero-point energy of the oscillatory motion is of the order of the energy of the rotational level $j=1$, and for smaller amplitudes the zero-point energy is even larger. Because of the small moment of inertia of the $\mathrm{H}_{2}$ molecule this zero-point energy for an oscillatory motion of $p-\mathrm{H}_{2}$ molecules would be large, of the order of $300 \mathrm{cal}$ or more. The Raman spectrum of hydrogen arising from transitions between rotational levels is the same for the gaseous and liquid phases ${ }^{17}$ to within the accuracy of the measurements showing that the rotational states are characterized by practically the same energy differences in the gaseous and liquid states. This makes it appear unlikely that liquid $p-\mathrm{H}_{2}$ could have a large zero-point oscillatory energy, and hence, the directions of orientation of the axes of the nonrotating $p-\mathrm{H}_{2}$ molecules in both the liquid and solid phases must be randomly distributed. In this respect of randomness of orientation of the axes of molecules, the state of nonrotating $p-\mathrm{H}_{2}$ is like that at high temperatures in other substances whose molecules are rotating, since for large rotational quantum numbers the distribution of the axes of the rotating molecules is practically uniform.

The axes of rotation of the $o-\mathrm{H}_{2}$ molecules in the liquid and solid phases are oriented. At temperatures below the critical point of hydrogen $\left(33^{\circ} \mathrm{K}\right)$, practically all $o-\mathrm{H}_{2}$ molecules are in the state $j=1$,

16 Augustin, Ann. Phys. 46, 419 (1915).

17 J. O. McLennan and J. H. McLeod, Roy. Soc. Canada, Trans. 23, section 3, 19-20 (1929). 
and the three possible orientations of the axis of rotation of an $0-\mathrm{H}_{2}$ molecule in liquid or solid hydrogen are characterized by the quantum numbers $m=0, \pm 1$. At $0^{\circ} \mathrm{K}$ all the $o-\mathrm{H}_{2}$ molecules are concentrated in the state of orientation ( $m$ state) having the lowest energy, and in the temperature range below $12^{\circ} \mathrm{K}$, in which the specific heat of solid $o-\mathrm{H}_{2}$ exceeds that of solid $p-\mathrm{H}_{2},{ }^{18}$ molecules are being raised to the $m$ states of higher energy. In the liquid and solid phases, the orientations of the axes of the $o-\mathrm{H}_{2}$ molecules are not randomly distributed in all possible directions as in the case of $p-\mathrm{H}_{2}$, hence $o-\mathrm{H}_{2}$ corresponds more nearly with other substances at low temperatures where their molecules are oriented and do not rotate, than with these substances at high temperatures where the molecules rotate.

The difference in molecular volumes of the condensed phases of $o$ - and $p-\mathrm{H}_{2}$ arises from a difference in the intermolecular forces. To the difference in intermolecular forces must also be attributed the difference in "lattice" energies responsible for the differences in vapor pressures of the ortho and para varieties. It is expected that the Van der Waals attractive forces will be very nearly the same for $o$ - and $p-\mathrm{H}_{2}$ since these forces arising from "orbital" electron resonance in neighboring molecules are not appreciably influenced by molecular rotation. However, the intermolecular forces of repulsion, which arise from the repulsion of regions of high electron density in neighboring molecules, must be different for 0 - and $p-\mathrm{H}_{2}$ since their distributions of electron charge density are different. It is then this difference in the distribution of the average electron-charge density that is responsible for the differences in molecular volume and vapor pressure.

Not only is there a difference in the magnitude of the intermolecular forces of $o$ - and $p-\mathrm{H}_{2}$, but there is also a difference in the symmetry, that is dependence on the angle, of the forces. In liquid and solid $o-\mathrm{H}_{2}$ the axes of rotation of the $o-\mathrm{H}_{2}$ molecules are oriented. The forces of molecular orientation in $0-\mathrm{H}_{2}$ arise from the nonspherical character of the average electron density of the rotating hydrogen molecule. The dependence of the electron density on the polar angle for the rotational state characterized by the quantum numbers $j, m$, is given by the square of the associated Legendre polymonial $P_{j, m}(\cos \theta)$, which expresses the dependence on $\theta$ of the $\psi$-function for the diatomic rotator ${ }^{19}$ For $p-\mathrm{H}_{2}, j, m=0,0,\left(P_{0},{ }_{0}\right)^{2}=1$; for $o-\mathrm{H}_{2}, j, m=1,0,\left(P_{1},{ }_{0}\right)^{2}$ $=\cos ^{2} \theta$ and for $o-\mathrm{H}_{2}, j, m= \pm 1,\left(P_{1},{ }_{1}\right)^{2}=\sin ^{2} \theta$. Thus the electron distribution of $p-\mathrm{H}_{2}$ at low temperatures is spherically symmetrical and no forces of orientation arise. For the $o-\mathrm{H}_{2}$ state of lowest energy, $j, m=1,0$, the electron distribution is densest along the polar axis, whereas for the states, $j, m=1, \pm 1$ it is densest over the equatorial plane. It is to be expected, therefore, that as the population of the three $m$ states of $o-\mathrm{H}_{2}$ changes, the forces of orientation will also change.

The average electron distribution for the three $m$ states of $o-\mathrm{H}_{2}$ $(j=1)$ is uniform over all directions as is seen by normalizing the $\psi$-functions for the three $m$ states and adding. Therefore, above about $12^{\circ} \mathrm{K}$ the average electron distribution of all the $o-\mathrm{H}_{2}$ molecules is uniform like that characteristic of $p-\mathrm{H}_{2}(j=0)$. At any instant,

\footnotetext{
18 Simon, Mendelssohn, and Ruhemann, Z. physik. Chem. [B] 15, 121 (1931). Also A. Farkas, Orthohydrogen, Parahydrogen, and Heavy Hydrogen, Cambridge University Press, p. 35-37 (1935).

19 See Ruark and Urey, Atoms, Molecules, and Quanta. p. 527-531, McGraw-Hill Book Co., New York, N. Y. (1930); A. Farkas, Orthohydrogen, Parahydrogen, and Heavy Hydrogen, p. 35-37, Cambridge University Press, (1935).
} 
however, an individual $o-\mathrm{H}_{2}$ molecule is in only one of the three $m$ states so that its electron distribution is not uniform but is that characteristic of its quantum number $m$ at that instant. Even at temperatures above $12^{\circ} \mathrm{K}$, then, there is a difference between the electron distributions of the individual ortho and para molecules. It is to this nonuniform electron distribution of the individual $o-\mathrm{H}_{2}$ molecules that is attributed the differences between the intermolecular forces and properties of the condensed states of $o$ - and $p-\mathrm{H}_{2}$ above $12^{\circ} \mathrm{K}$.

From the difference between the specific heats of solids $o$ - and $p$ $\mathrm{H}_{2}$, it is possible to determine the magnitude of the force of orientation in solid $o-\mathrm{H}_{2}$. In an $o-\mathrm{H}_{2}$ crystal whose molecules are all in the state, $j, m=1,0$ the molecules will orient themselves so that their angular velocity vectors are aligned perpendicular to the principal axis of the hexagonal crystal. The potential of the orienting force may be represented to a first approximation by equation $V=V_{0}(1-\cos 2 \theta)$ $=2 V_{0} \sin ^{2} \theta$. In the presence of a force of molecular orientation given by this equation the energies of the states, $j, m=1, \pm 1$ are greater ${ }^{20}$ than the energy of the state, $j, m=1,0$ by $4 / 5) V_{0}$. The value of $V_{0}$ calculated from the difference between the specific heat of solid 100percent $p-\mathrm{H}_{2}$ and the specific heat of solid mixtures of $o-$ and $p-\mathrm{H}_{2}{ }^{21}$ at $7^{\circ} \mathrm{K}$ is about $14 \mathrm{cal} \mathrm{mole}^{-1}$. The value of $V_{0}$ calculated from the difference in specific heats at higher temperatures is smaller $(9 \mathrm{cal}$ mole ${ }^{-1}$ at $10^{\circ} \mathrm{K}$ ). This difference is in agreement with a change expected in the forces of molecular orientation as the population of the three $m$ states changes.

It seems probable that the mutual repulsion of regions of high electron density will permit a closer packing of $o-\mathrm{H}_{2}$ molecules with high electron density along a line $(m=0)$, than $0-\mathrm{H}_{2}$ molecules with high density over a plane $(m= \pm 1)$. This makes the $o-\mathrm{H}_{2}$ state $j, m=1,0$ the low energy state of $o-\mathrm{H}_{2}$ stable at $0^{\circ} \mathrm{K}$ as was assumed in the preceding paragraph rather than either of the states $j, m=1, \pm 1$. The specific-heat data are in accord with this, as will now be shown. The angular velocity vectors of the molecules in a crystal of $o-\mathrm{H}_{2}$ all in the states, $j, m=1, \pm 1$ would be directed along the principal axis of the hexagonal crystals so that the potential of the orienting force could be represented to a first approximation by the equation $V=V_{0}$ $(1+\cos 2 \theta)=2 V_{\mathrm{o}} \cos ^{2} \theta$. For this case we find that the energy of the state $j, m=1,0$ is greater than that of the states $j, m=1, \pm 1$ by $(4 / 5) V_{0}$, which leads to a maximum value of $0.48 \mathrm{cal}^{\circ} \mathrm{K}^{-1}\left(\text { mole of } 0-\mathrm{H}_{2}\right)^{-1}$ for the difference between the specific heats of solid $p-\mathrm{H}_{2}$ and a solid solution of $o-\mathrm{H}_{2}$ and $p-\mathrm{H}_{2}$ assuming $V_{0}$ is independent of the temperature. The experimentally measured specific heat of a solid solution containing 50 percent of $0-\mathrm{H}_{2}$ exceeds that of solid $p-\mathrm{H}_{2}$ at $5^{\circ} \mathrm{K}$ by $0.79 \mathrm{cal}^{\circ} \mathrm{K}^{-1}$ (mole of $\left.o-\mathrm{H}_{2}\right)^{-1}$ and at this temperature, the lowest reached in the calorimetric experiments, the difference is increasing toward lower temperatures. It seems more reasonable that the lowenergy state of $o-\mathrm{H}_{2}$ is the state $j, m=1,0$, than that this difference in specific heats is to be attributed to the rapid rate of decrease of $V_{0}$ with temperature (larger than $8 \mathrm{cal}^{\circ} \mathrm{K}^{-1}\left(\text { mole of } o-\mathrm{H}_{2}\right)^{-1}$ ) needed to account for it if the low-energy state is $m=+1$ or -1 .

It is customary to represent graphically the intermolecular forces in a condensed phase by the "lattice potential-energy curve" and to

${ }^{20} \mathrm{Scott}$, Brickwedde, Urey, and Wahl, J. Chem. Phys. 2; 458 (1934).

${ }_{21}$ See footnote 18. 
use this curve in demonstrating in a qualitative manner properties of the condensed phase. If the Van der Waals attractive forces are very nearly the same for $o$ - and $p-\mathrm{H}_{2}$, the potential-energy curves of the ortho and para varieties coincide at large values of the distance between the molecules (fig. 2). The repulsive forces are different for $o$ - and $p-\mathrm{H}_{2}$ and the two curves deviate from each other at small intermolecular separations. The nearly equal expansivities and specific heats above $12^{\circ} \mathrm{K}$ of solid and liquid 0 - and $p-\mathrm{H}_{2}$ are in accord with the similar shapes of the two curves. Actually, the expansivity of $p-\mathrm{H}_{2}$ is slightly larger than that of $o-\mathrm{H}_{2}$, and this difference is in the direction to be accounted for by the two curves as represented in figure 2.

At $0^{\circ} \mathrm{K}$, at which temperature the $0-\mathrm{H}_{2}$ molecules are concentrated in the state $m=0$, it is probable that the force of orientation is most

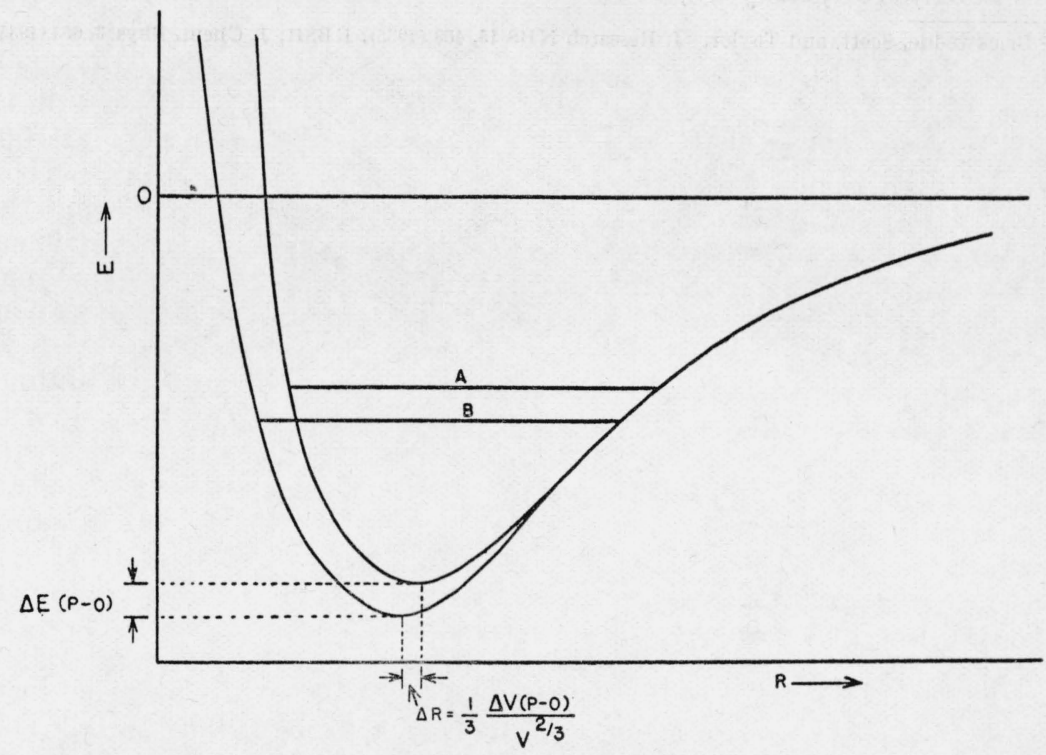

FIGURE 2.-Diagram illustrating the relation of the "lattice potential-energy curves" of $p$ - and $o-\mathrm{H}_{2}$ in which the lattice potential energy $E$ is represented as a function of the intermolecular distance $R$ as abscissa.

Horizontal lines $A$ and $B$ represent the lattice energies, kinetic and potential, of $p-$ and $o-\mathrm{H}_{2}$ at some temperature, the same for both $p-$ and $0-\mathrm{H}_{2}$. This figure is not drawn to scale.

intense and the difference in molecular volume of the ortho and para varieties is largest. In the temperature range in which the population of the states $m= \pm 1$ is changing rapidly, the difference in molecular volumes and the relative positions of the potential-energy curves will change most rapidly. As the temperature is raised above $12^{\circ} \mathrm{K}$, the increasing thermal agitation will interfere to a greater and greater extent with the alignment of the $0-\mathrm{H}_{2}$ molecules, and the potentialenergy curve of $0-\mathrm{H}_{2}$ will move towards that of $p-\mathrm{H}_{2}$. For solutions of $o-\mathrm{H}_{2}$ and $p-\mathrm{H}_{2}$, the average potential-energy curve will lie between those of its pure constituents, its exact position and the forces of orientation depending upon the concentration. 
It was shown in a previous paper ${ }^{22}$ that the vapor pressure of the nonrotating $0-\mathrm{D}_{2}$ is greater than that of the rotating $p-\mathrm{D}_{2}$ and in this respect $o-\mathrm{D}_{2}$ corresponds to $p-\mathrm{H}_{2}$. It was further demonstrated that the ortho-para vapor-pressure difference of $\mathrm{D}_{2}$ is comparable in magnitude with that of $\mathrm{H}_{2}$. Hence it is expected that there is a difference in the molecular volumes of $o-\mathrm{D}_{2}$ and $p-\mathrm{D}_{2}$ comparable in magnitude with the difference in molecular volumes of $p-\mathrm{H}_{2}$ and $o-\mathrm{H}_{2}$, the molecular volume of $o-\mathrm{D}_{2}$ being greater than that of $p-\mathrm{D}_{2}$.

The authors thank Prof. Edward Teller for the opportunity of discussing the results of this experiment with him and for the helpful suggestions he made.

W ASHington, May 27, 1937.

${ }^{22}$ Brickwedde, Scott, and Taylor. J. Research NBS 15, 463 (1935), RB841; J. Chem. Phys. 3, 653 (1935) 